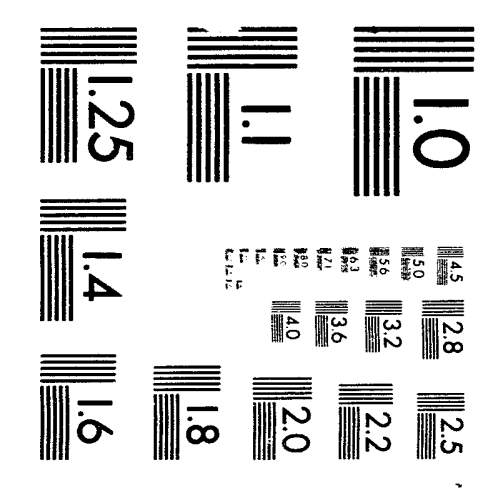



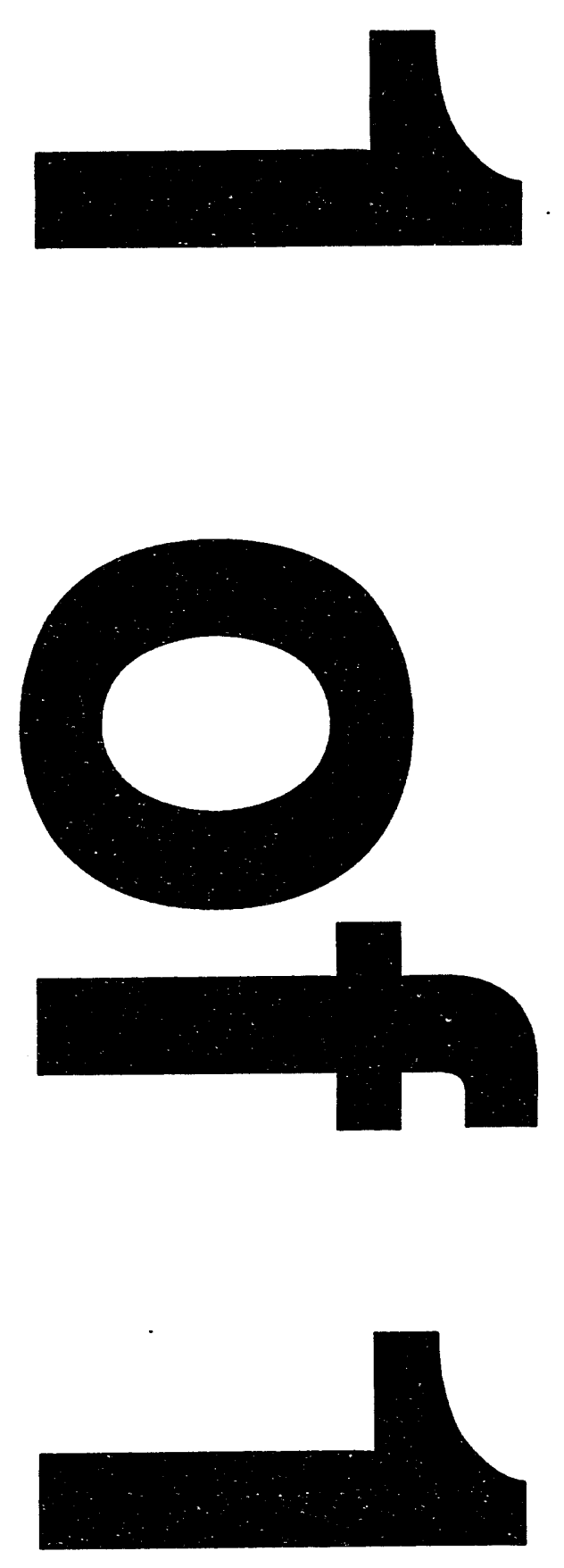


\title{
Interstrand Resistance of Selected Sections of DCA312
}

\author{
V. Kovachev, M. Neal, J. Seuntjens, \\ J.Qin, P. Cline, and D. Capone II
Superconducting Super Collider Laboratory*
2550 Beckleymeade Ave.
Dallas, TX 75237 USA \\ C. Swenson \\ Westinghouse Electric Corporation \\ I-H 35 North at Westinghouse Road \\ Round Rock, TX 78681
}

November 1993

*Operated by the Universities Research Association, Inc., for the U.S. Department of Energy under Contract No. DE-AC35-89ER40486. 


\section{INTERSTRAND RESISTANCE OF SELECTED SECTIONS OF DCA312}

V. T. Kovachev, M. J. Neal, J. M. Seuntjens, J. Qin,

P. G. Cline, C. Swenson ${ }^{\dagger}$, and D. W. Capone II

Superconducting Super Collider Laboratory*

2550 Beckleymeade Ave. Dallas, TX 75237-3997

†Westinghouse Electric Corporation

I-H 35 North at Westinghouse Road

Round Rock, TX 78681

\section{INTRODUCTION}

The quench current ramp rate sensitivity of the full length SSC dipole DCA312 was strongly A-type ${ }^{1}$ and the eddy current losses for this magnet were the largest of all ASST magnets ${ }^{2}$. The quench current remained constant with ramp rate up to approximately $20 \mathrm{~A} / \mathrm{s}$. At higher ramp rates the quench current decreased dramatically. At a current ramp rate of $200 \mathrm{~A} / \mathrm{s}$ the quench current was only $2000 \mathrm{~A}$. The eddy current losses of DCA312 at $60 \mathrm{~A} / \mathrm{s}$ for a monopolar cycle of 500A-5000A-500A were approximately $3600 \mathrm{~J} /$ Cycle, a factor of 5-7 larger than for magnets DCA311, DCA319, and DCA318.

In order to find the cause of the anomalous behavior of DCA312, it was decided that the magnet would be cut into sections and examined at WMSD and SSCL. The general goals of the DCA312 autopsy included verification of thecietical models for A-type behavior in SSC magnets as well as correlation of fabrication and assembly procedures to the quench behavior of A-type magnets ${ }^{3}$. One of the important aspects of the magnet autopsy plan was the in-situ

\footnotetext{
*Operated by the Universities Research Association, Inc., for the U.S. Department of Energy under Contract No. DE-AC35-76SF00098.
} 
measurement of interstrand resistance in collared magnet sections. Four sections of DCA312 were designated for interstrand resistance measurements. Two of those sections (C and $M$ ) contained quench sites (100 A/s and $200 \mathrm{~A} / \mathrm{s}$ respectively) and two of them (E and $\mathrm{J}$ ) were sections representative of the magnet where quenches did not occur.

The aim of the present work was to measure and analyze the interstrand resistance in each quadrant of these four sections of DCA312 and to find a correlation between the me isured interstrand resistance, the actual resistance of individual interstrand contacts, and the quench performance of the magnet.

\section{EXPERIMENTAL}

\section{II.1 High Ramp Rate Quenches of Magnet DCA 312}

The ramp rate quench performance of DCA312 was remeasured at BNL in early January 1993 and reported to be nearly identical to the previous FNAL results, despite a difference in helium flow rates into the magnet during the tests at BNL and FNAL. According to the quench test data the $100 \mathrm{~A} / \mathrm{s}$ quenches occurred in the inner coil $6.95 \mathrm{~m}$ from centerline to the non lead end of the magnet and azimuthally between $141^{\circ}$ and $177^{\circ}$ counterclockwise from the right hand horizontal axis as viewed from the lead end of the magnet. This region incorporates turns 2 through 11 of quadrant 1 as viewed from the magnet non-lead end. The $200 \mathrm{~A} / \mathrm{s}$ quenches occurred in the inner coil $4.17 \mathrm{~m}$ from centerline to non-lead end of the magnet azimuthally between $22^{\circ}$ and $36^{\circ}$ counterclockwise from the right hand horizontal axis as viewed from the lead end of the magnet. This region incorporates turns from 7 through 11 of quadrant 3 as viewed from the magnet non-lead end.

\section{II.2 Preparation of Magnet Sections}

Four sections of the magnet DCA312 were prepared for in situ interstrand resistance measurements. The yokes of these sections were removed but the collars were left on the tested region of each section. All four keys were spot-welded every $2-3 \mathrm{~cm}$ in a zig-zag manner on both key sides of the collars to insure that collar pressure was maintained. The collared portion was approximately one cable twist pitch $(88 \mathrm{~mm} \pm 5 \%)$ in length. The collars were removed from an approximately $45-65 \mathrm{~mm}$ length of inner coil cable for purposes of making electrical connection to the strands.

The magnet section was cut using a horizontal bandsaw with a fine tooth blade (18 teeth per inch) at a speed of $80 \mathrm{fpm}$. The blade had a downward force of around 5 psi and the cut was made using a water soluble cutting fluid. It took $1.5 \mathrm{hrs}$ to saw through the magnet section. The collars were removed using a hammer and chisel. Afterwards a lathe (set on $80 \mathrm{rpm}$ ) was used to machine the outer coil down until only 1 wire diameter was left holding the coil section in place. The remaining wire was fatigued off and the outer coil section removed. Each section was polished at the collared end using an Automet polisher set on 150 RPM. The following grits of silicon carbide sandpaper were used for a duration of 5 minutes each: 120, 180, 240, 320, 400 and 600 . The sample was washed with water between each grit to reduce carry over. Each section was then etched with a solution of $20 \%$ Nitric acid in water for $15-20$ seconds. The section was then rinsed with water and inspected with a $10 \mathrm{X}$ microscope to make sure there was no smearing of copper between the strands which might result in erroneous resistance readings when tested. 


\section{II.3 Test Procedure}

The in situ interstrand resistance measurements were performed using the procedure and equipment previously reported ${ }^{1}$, with the exceptions that the set of strands within a turn and the set of turns within a section chosen for testing were modified. The turns of the inner coils were labeled in the conventional manner from 1 (midplane turn) to 19 (pole tum) and the upper and lower coils were labeled A and B, respectively. Coil A of the magnet exists in quadrants I and II and coil B in quadrants III and IV. The strands in a turn are numbered from 1 to 30 counterclockwise from the inside minor edge at the top of the uncollared section of the cable. Using this scheme each strand length tested is uniquely identified by its magnet section, quadrant, cable tum and strand number.

Typically a set of 9 turns from each quadrant was tested. These nine turns were: $1,3,6,7$, $13,14,16,17$, and 19. In addition all turns in the regions identified as quench locations were tested. The quench locations were: section $\mathrm{C}$, quadrant $\mathrm{I}$, turns $2-11(100 \mathrm{~A} / \mathrm{s}$ quench) and section $\mathrm{M}$, quadrant II, turns 7-10 (200 A/s quench).

Eight of the thirty strands in a cable turn were instrumented for interstrand resistance testing. This set of strands was chosen to include the six strand set used in previous work and to increase the variety of strand separations tested with a minimal increase in the total number of measurements. The sample set consisting of strands $1,2,6,8,11,16,21 \& 26$ is shown in Figure 1. These strands were tested in all possible pairings resulting in a total of 28 interstrand resistance measurements from each turn. In addition to the standard sample set all thirty strands of one turn (Section E, quadrant III, turn 19) were tested. A total of 112 interstrand resistances were measured, including resistance between all adjacent strands. This more complete sampling, the results of which are presented and discussed in Appendix II, was performed to establish the validity of the standard sample set .

Resistances were calculated from a measuring current of $30.0 \mathrm{~A}$ and a measured voltage ranging from approximately 1 to 100 microvolts using a standard four probe technique. The voltage used in the calculation was the average of 200 consecutive readings taken at $25 \mathrm{~ms}$ intervals using the data storage function of the Keith' y 182 Sensitive Digital Voltmeter. Voltage averages were reproducible to within 5\%, irrespective of thermal cycling and reinstrumentation of current and voltage contacts.

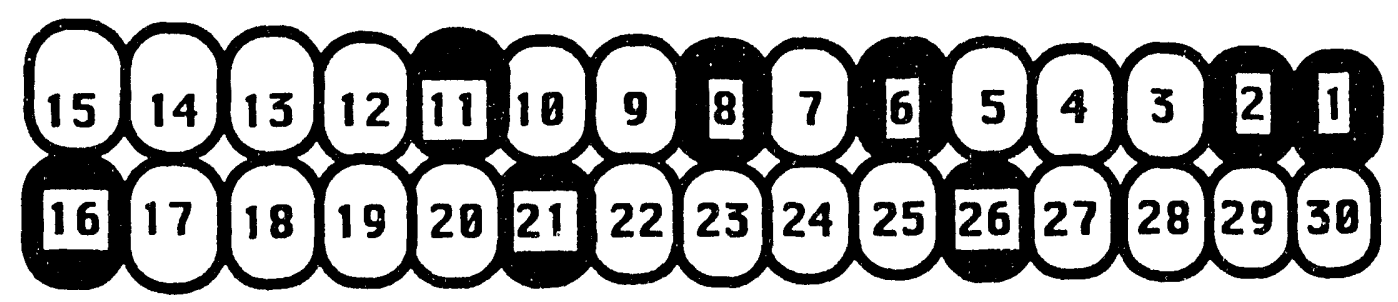

Figure 1 Sketch of cable cross section with tested strands shaded.

\section{RESULTS AND DISCUSSION}

The entire set of data for the interstrand resistance of sections C, E, J, and M of DCA312 inner coil is presented in Appendix I. The results are shown as plots of measured average and adjacent strand resistance, and evaluated adjacent strand and crossover resistance, all as a 
function of turn number. The measured interstrand resistances represent approximately 8700 resistance values, each one calculated from the average voltage described earlier using a Microsoft Excel 4.0 spreadsheet package. The evaluation of single crossover and adjacent contact resistances was carried out by the Excel 4.0 program using the analytical model previously described ${ }^{1}$.

\section{III.1 Quench regions}

Figure 2 shows measured adjacent interstrand resistance and average measured interstrand resistance vs turn number for section C, QI as representative of a quench site portion of the magnet inner coil. The average measured resistance was obtained taking the average of all interstrand resistances measured regardless of the strand separation number. One can see that throughout most of the quench region (turn \#2 through turn \#11) both the adjacent and the average measured resistances are as low as $30-50 \mathrm{n} \Omega$. A special feature of the quench region is that the average measured resistance is rather close to the measured adjacent resistance which suggests that the cable there has reduced anisotropy of effective resistivity ${ }^{4}$ and that the effective resistivity, in general, is very low. Similar behavior of the measured interstrand resistances can be seen at the $200 \mathrm{~A} / \mathrm{s}$ quench site (see Appendix I, Section M, QII) which supports the conclusion made above that the cable is like a solid bar of a nearly isotropic metal.

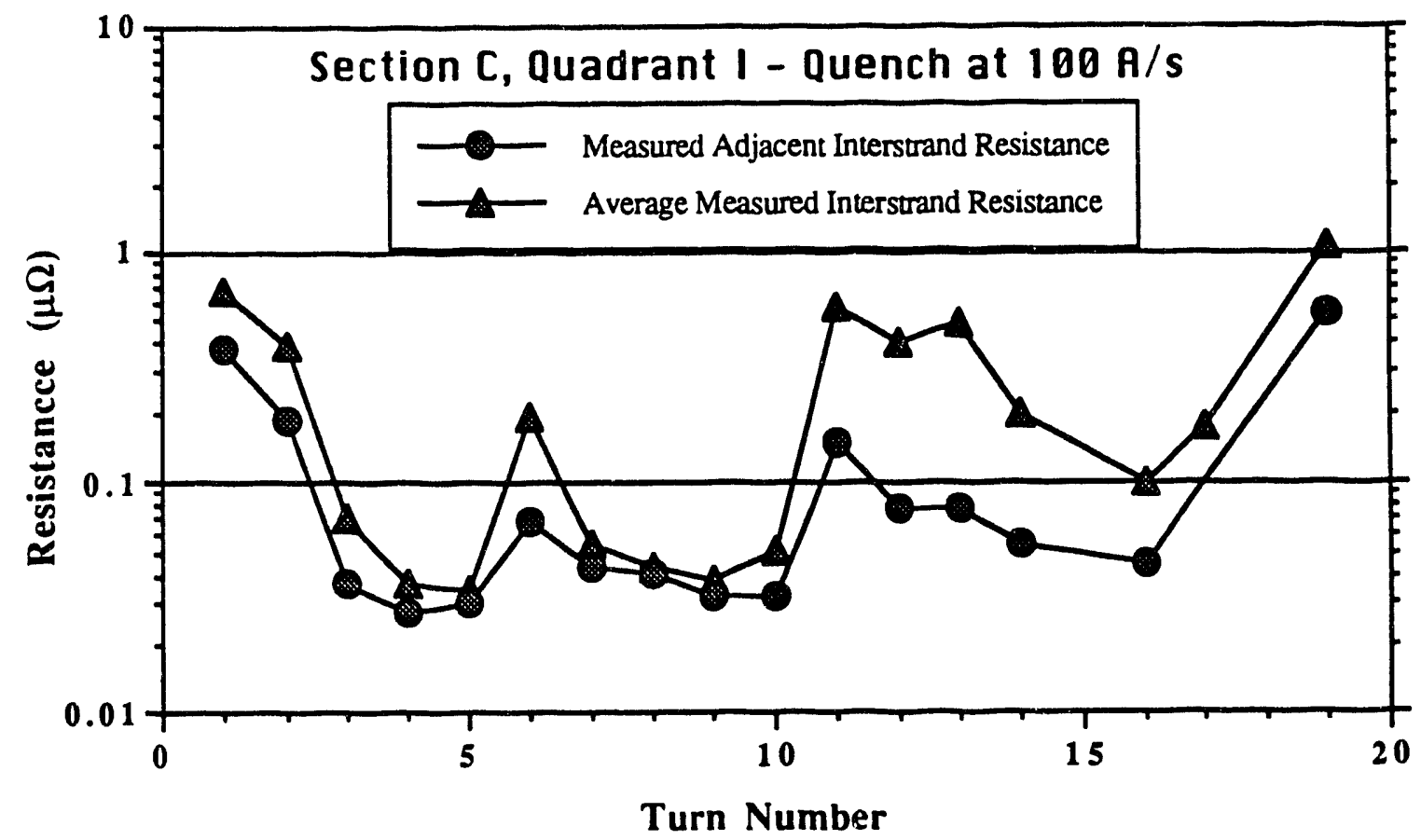

Figure 2. Measured interstrand resistance in section C, quadrant I of magnet DCA 312, measured at each cable turn from the midplane (1) to pole (19) turns.

Figure 3 shows calculated individual adjacent $\left(\mathrm{r}_{\mathrm{adj}}\right)$ and crossover $\left(\mathrm{r}_{\mathrm{co}}\right)$ resistances vs. turn number for section C, QI. Adjacent resistances are evaluated per one cable pitch length and crossover resistances are per point contact ${ }^{1}$. It can be seen from Figure 3 that $\mathrm{Ico}_{\mathrm{co}}$ in the quench region is on the order of $1 \mu \Omega$ and $\mathrm{radj}_{\mathrm{j}}$ is in the range of $0.08-0.7 \mu \Omega$. The ratio $\mathrm{r}_{\mathrm{co}} / \mathrm{radj}_{\mathrm{at}}$ at the quench site varies from about 2 to 100 (see Appendix I) but in the middle of the quench site 
remains equal to or less than 10 with the exception of the turn near the wedge (turn \#6). The analytical model used to evaluate $r_{c o}$ is in principal much more accurate at values less than about $100 \mu \Omega$ than at higher levels. This is because large crossover resistances result from ordinate intercepts very near zero in the linear fit method described previously 1 . These intercepts are the product of the crossover conductance and the number of strands so that small changes in the intercept near zero result in large variations in crossover resistance.

\section{III.2 Non-Quench Regions}

Figure 4 shows the measured adjacent and the average measured interstrand resistance for section J, QII in which quenches have never occurred. Typically the interstrand resistance of non-quench sites is higher than at quench sites. As shown on Figure 4, in section J, QII the adjacent resistance is about $0.1 \mu \Omega$ and most of the average measured crossover resistances are in the range of $0.3-0.7 \mu \Omega$. In some turns of non-quench sites the resistance is quite low (see Appendix I) and there is a rather close match between the adjacent and crossover resistances. However, in most of those cases either the neighboring turns have both adjacent and crossover resistances that are relatively large or the adjacent and crossover resistances are different. The latter can not be taken as completely proven fact because not all of the neighboring turns have been measured.

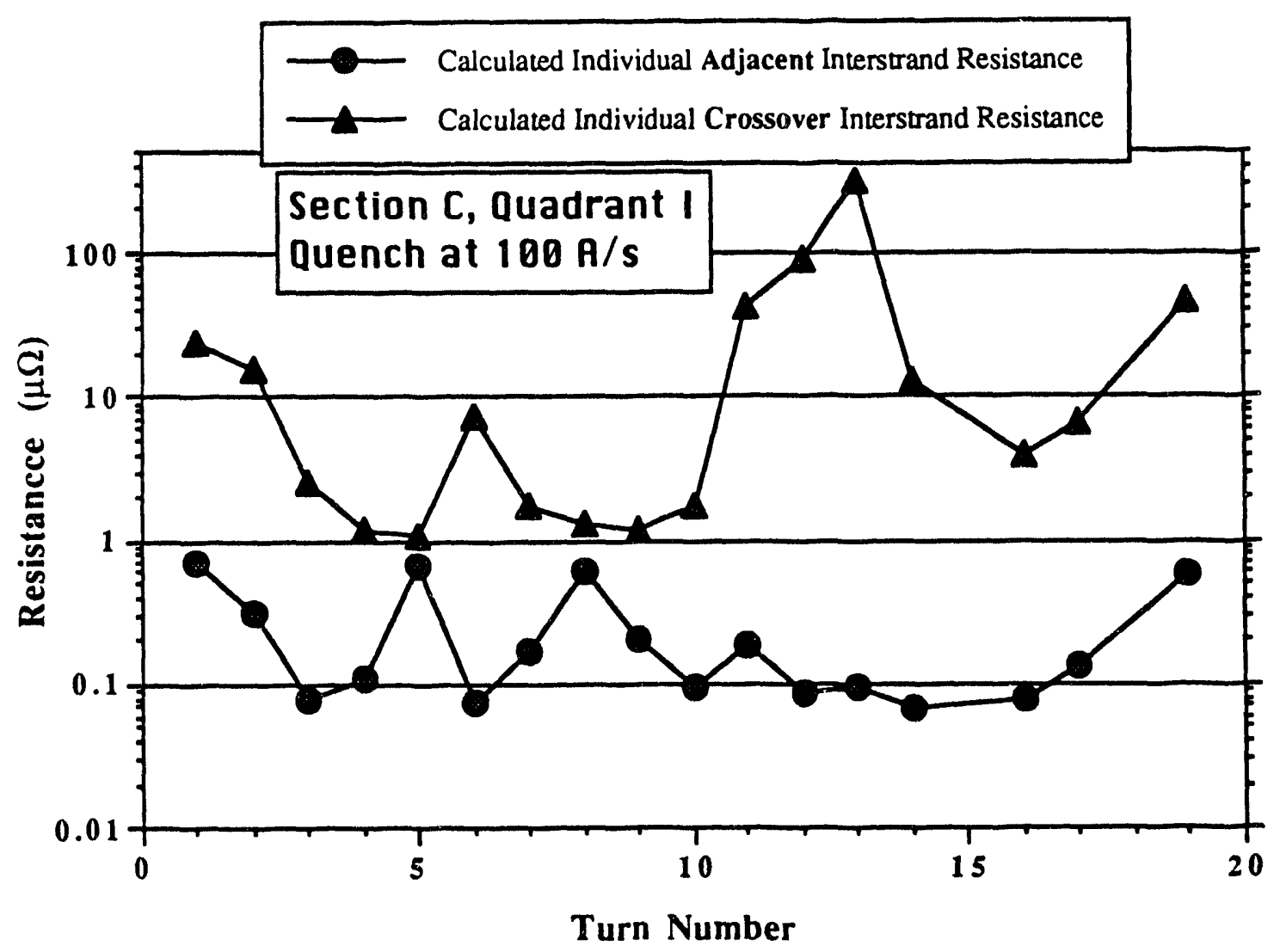

Figure 3. Crossover and adjacent resistances from the $100 \mathrm{~A} / \mathrm{s}$ quench region of magnet DCA 312 (section C, quadrant I), calculated from a linear fit to measured interstrand conductance as a function of $N /\left(N n-n^{2}\right)$. 


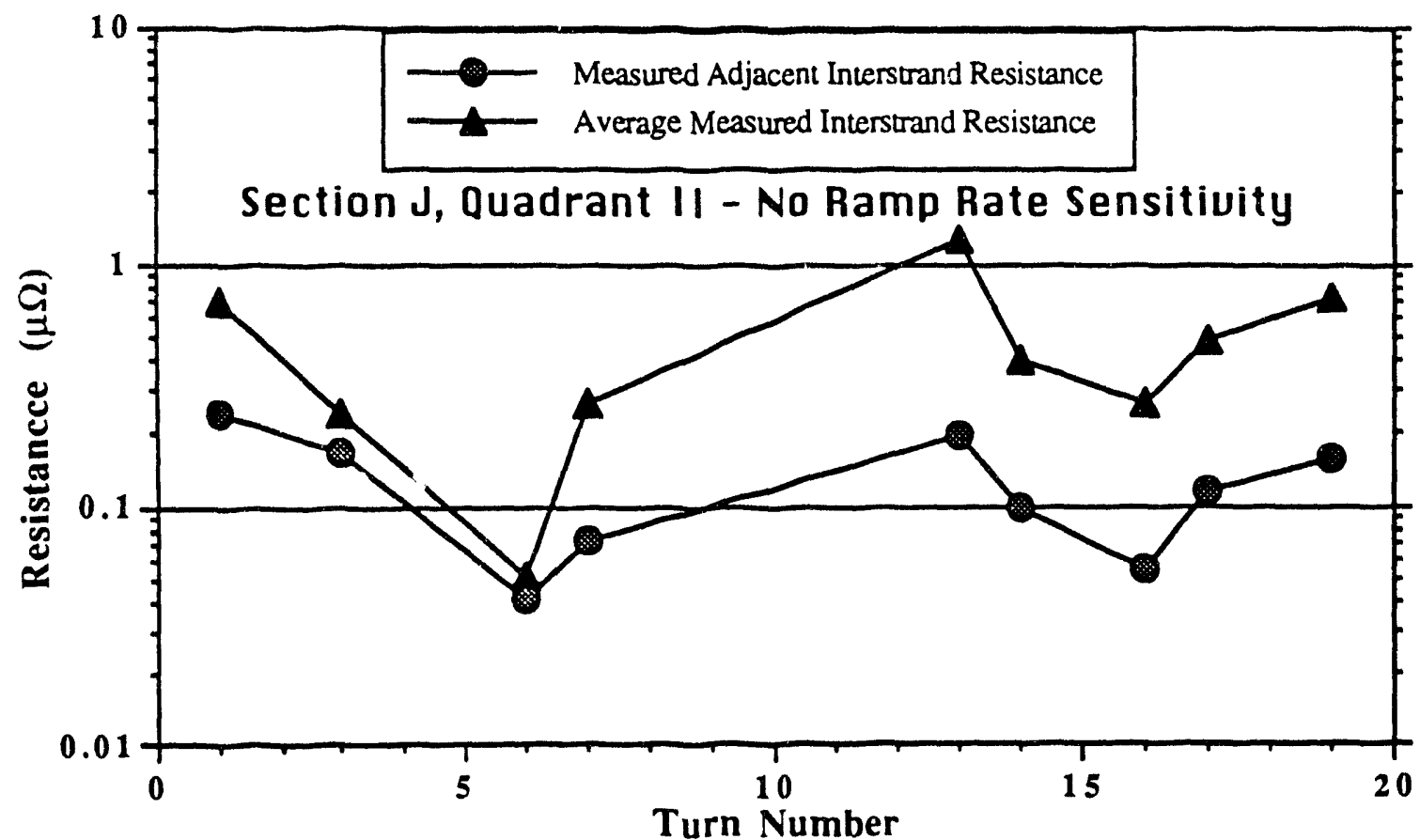

Figure 4. Measured interstrand resistance in a non-ramp rate sensitive region (section J, QII) of magnet DCA 312 plotted as a function of turn. number.

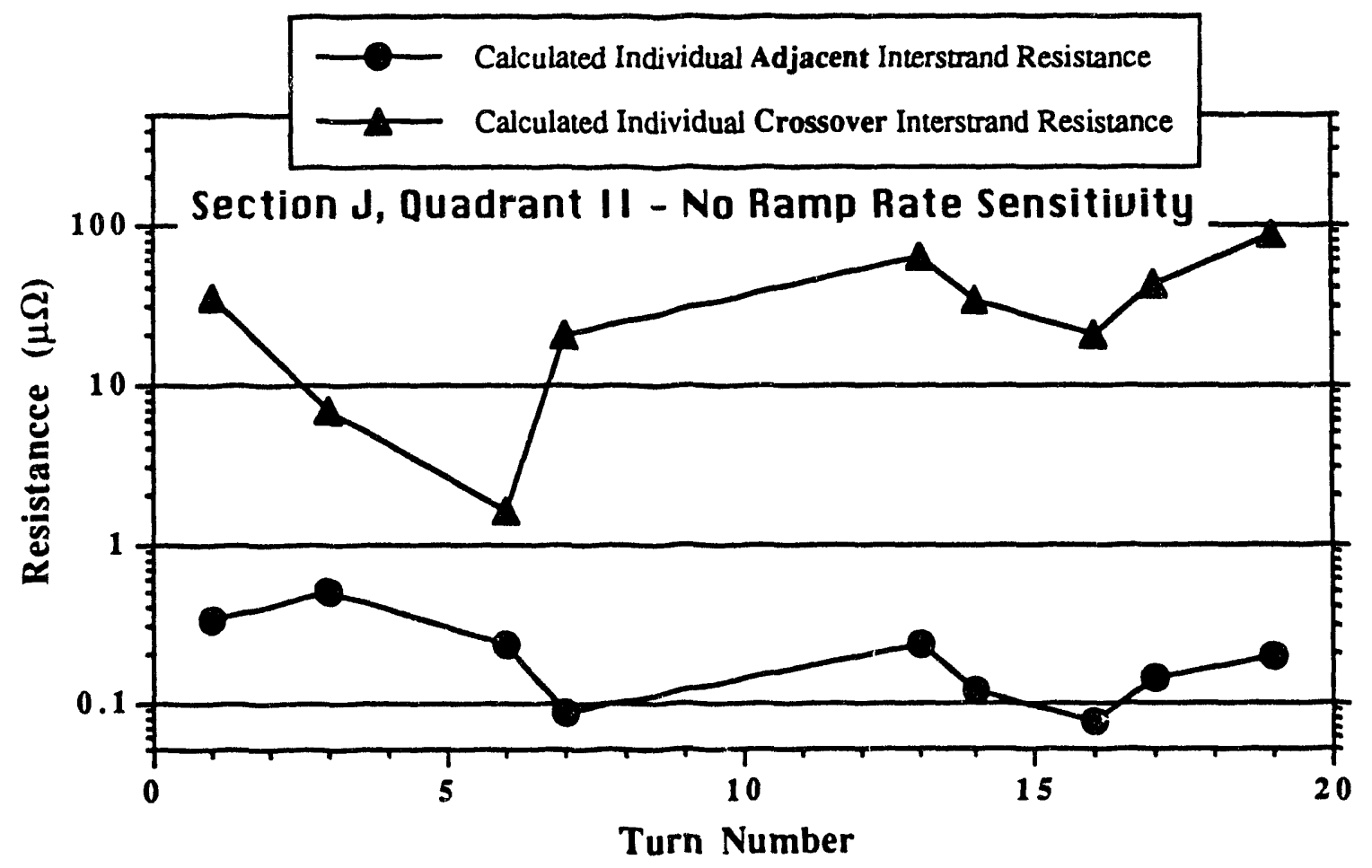

Figure 5. Crossover and adjacent interstrand resistances from a non ramp rate sensitive region of magnet DCA 312 (section J, QII), calculated from a linear fit to measured interstrand conductance as a function of $N /\left(N n-n^{2}\right)$. 
Figure 5 shows calculated individual adjacent $\left(\mathrm{r}_{\mathrm{adj}}\right)$ and crossover $\left(\mathrm{r}_{\mathrm{co}}\right)$ resistances vs. turn number for section J, QII. It can be seen that $\mathrm{r}_{\mathrm{co}}$ of a non-quench section is primarily in the range of 10-100 $\mu \Omega$ and $r_{a d j}$ is equal to or higher than $0.1 \mu \Omega$. The ratio $r_{c o} / r_{a d j}$ at the non-quench sites varies from about 7 to 500 (see Appendix I) but generally remains higher than 100 .

\section{III.3 Distribution of Average Resistance}

It has been reported previously ${ }^{1}$ that the average interstrand resistance of DSA328 inner coil does not confirm the interstrand resistance distribution evaluated from multipoles decay measurements ${ }^{5}$. However, in the case of DCA312 it can be clearly seen that the interstrand resistance tends to rise towards the midplane turn. This fact is in qualitative agreement with the interstrand resistance distribution evaluated from multipoles decay measurements. As an illustration, the total (throughout all sixteen quadrants) average measured resistance vs. turn number is shown in Figure 6. One can see that there is a clear tendency of the resistance to go down from the pole turn and than to go up towards the midplane besides sorne anomalies near the wedges. The maximum and minimum average measured resistances at each turn are indicated by the error bar symbols.

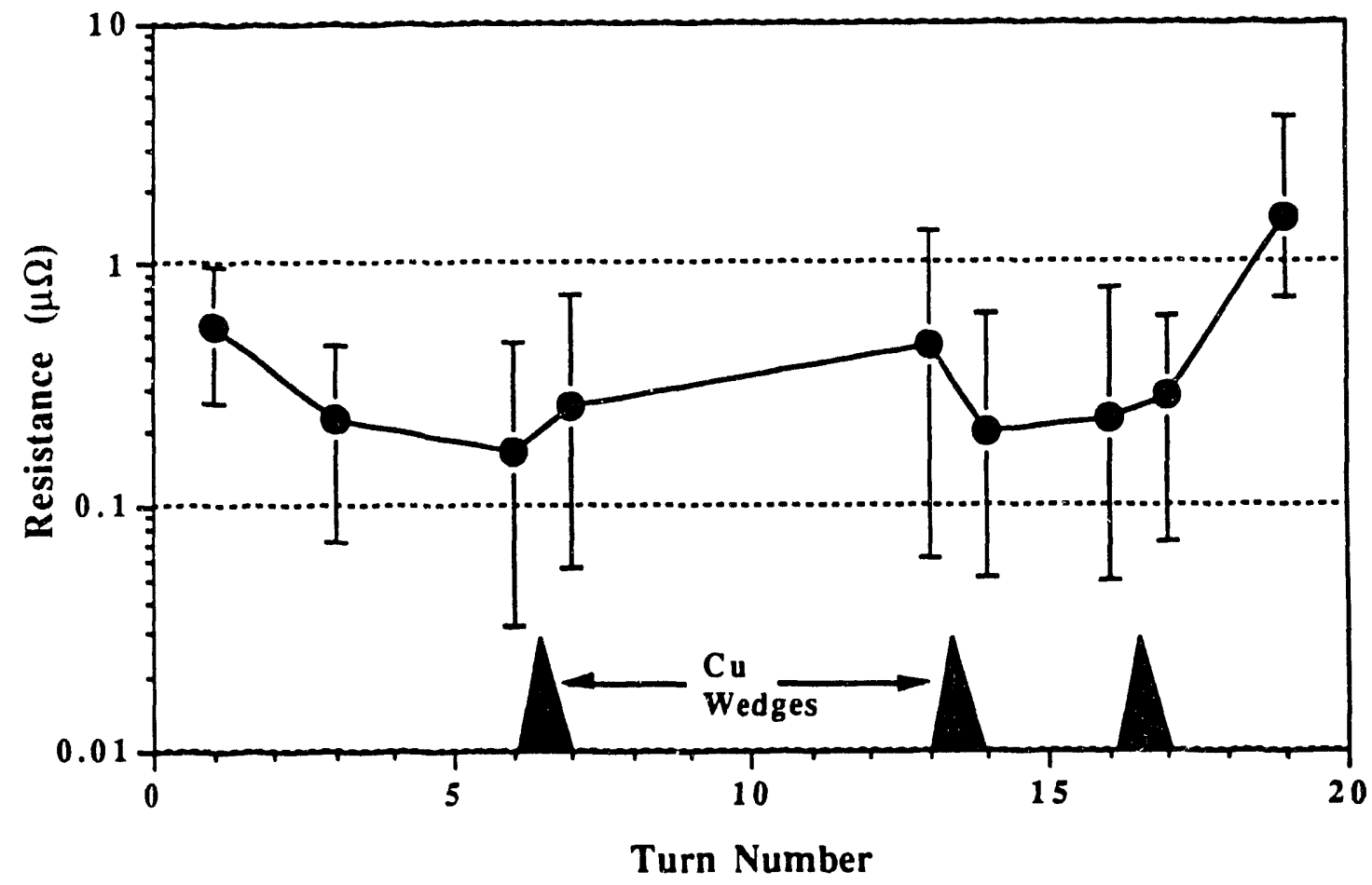

Figure 6. Distribution of average measured interstrand resistance at each coil turn for all test sections. The position of the copper wedges is also depicted.

\section{CONCLUSIONS}

1. The entire inner coil of DCA312 has relatively very low interstrand resistance. The adjacent strand contact resistance for one cable pitch length is typically in the $0.1-1.0 \mu \Omega$ range, but in some turns it can be as low as $50 \mathrm{n} \Omega$. The crossover resistance is typically in the range of $1-100 \mu \Omega$. These low interstrand resistances result in strong electromagnetic coupling between 
the strands and large cable eddy current losses during the field/transport current ramp. Low interstrand resistances obtained in this work are qualitatively consistent with the AC loss measurements results of DCA312.

2. The crossover resistances in the high ramp rate quench sites are typically much lower than those in non-quench sites of the coil. The adjacent strand resistance is essentially the same for the entire coil. The ratio of the crossover resistance to the adjacent strand resistance for the quench sites is normally between 1 and 10. This ratio for the non - quench regions is usually an order of magnitude higher.

3. The average interstrand resistance decreases from the pole turn and increases again towards the midplane. The interstrand resistance distribution obtained in this work is reminiscent of the $U$-shaped curve evaluated for the interstrand distribution from multipoles decay measurements.

4. The interstrand resistance distribution curve for DCA312 shows some irregularities of the interstrand resistance around the wedges. Such irregularities were observed in the inner coil of DSA328. Clearly, the coil preparation technology and/or coil assembly procedure affect the interstrand resistance in the coil around the wedges.

5. The interstrand resistance in some cable turns can vary along the magnet axis by an order of magnitude. This can probably be attributed either to an initial non-uniformity in the cable and/or to non-uniformity of coil preparation and assembly.

\section{ACKNOWLEDGMENTS}

The authors wish to thank T. Jarrett and J. Madison for helping with sample preparations and measurements.

\section{REFERENCES}

1). V. T. Kovachev, M. J. Neal, J. M. Seuntjens, J. Madison, S. Graham, P. G. Cline, M. Wake, and D. W. Capone II, Interstrand Resistance of DSA328 Coil, SSCL-637, August 1993.

2). M. Wake, Ramp rate behavior of SSC magnets, MSD Technical Note \# MD-MKA-0-93-007, SSCL, June 23, 1993.

3). C. Swenson, Magnet Autopsy Test PIan: DCA312, WMSD, March 1993.

4) W.J. Carr, Jr. , Interstrand Eddy Current Losses in SSC magnets, unpublished.

5). T. Ogitsu et. al., Influence of eddy currents on magnetic field harmonics, Proc. ICFA Workshop on AC Superconductivity, 23, KEK, Tsukuba, Japan, 1992 


\section{APPENDIX I \\ DCA 312 - C}
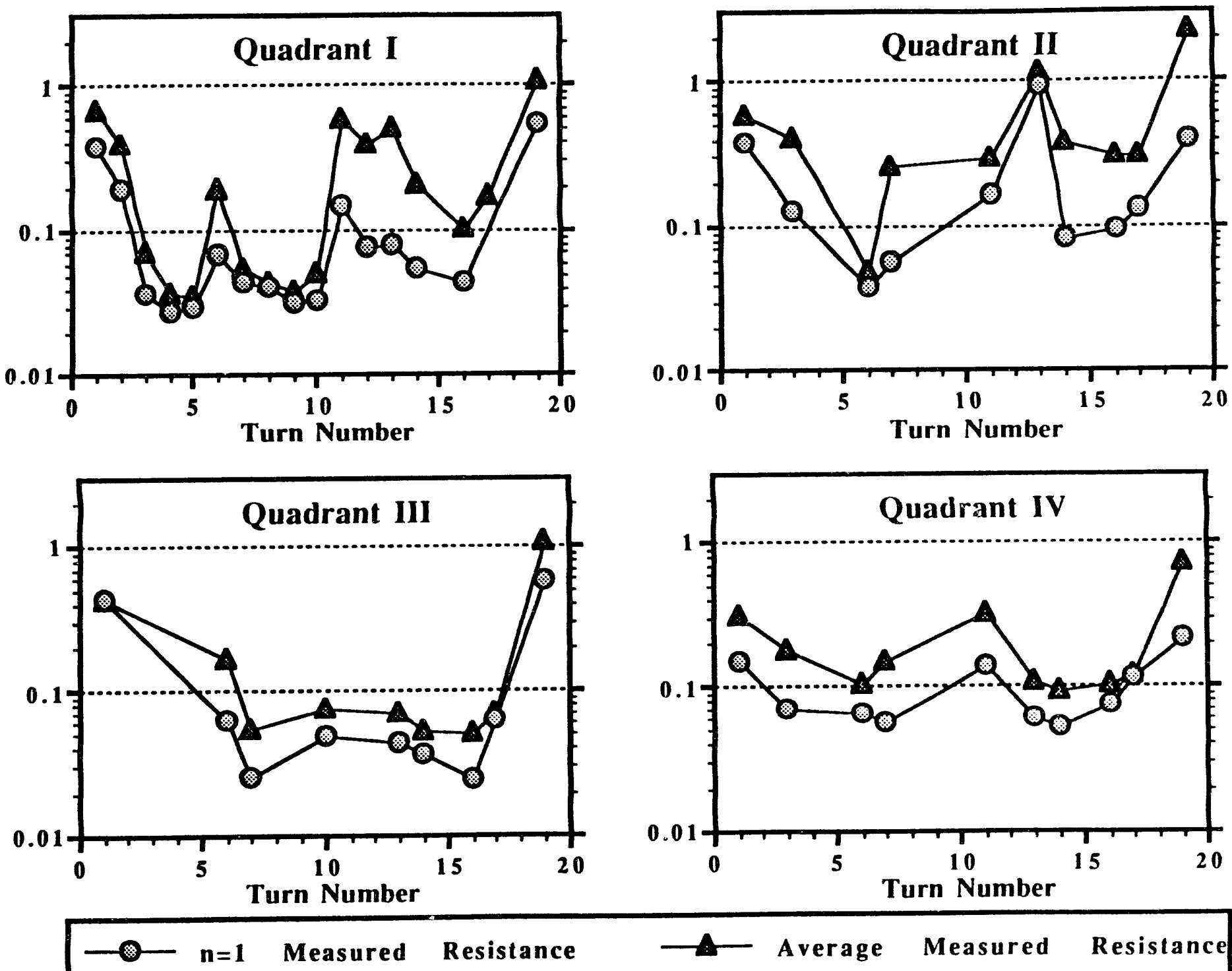

$\longrightarrow$ Average Measured Resistance 


\section{DCA 312 - E}
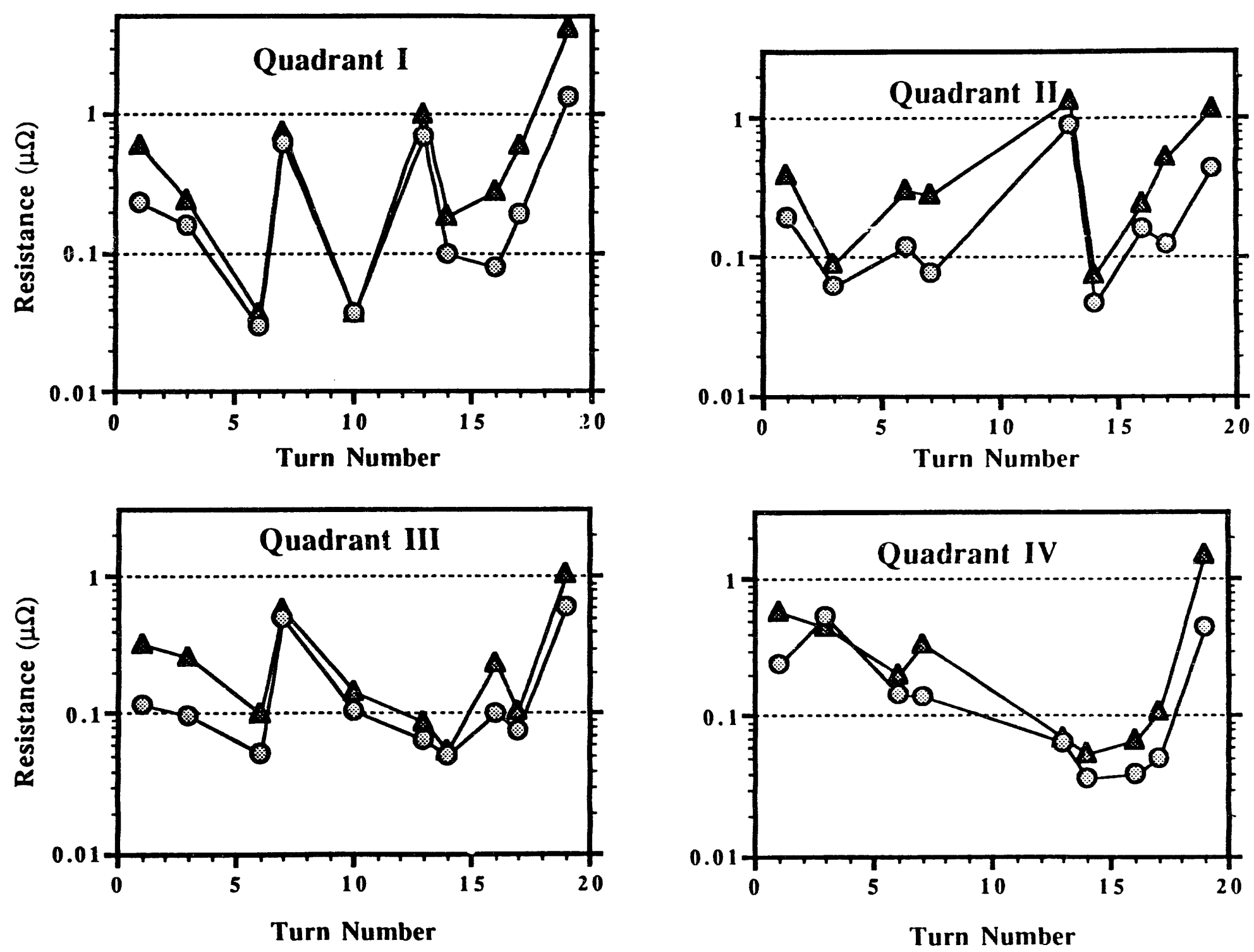

- 2 - $n=1$ Measured Resistance

A Average Measured Resistance 

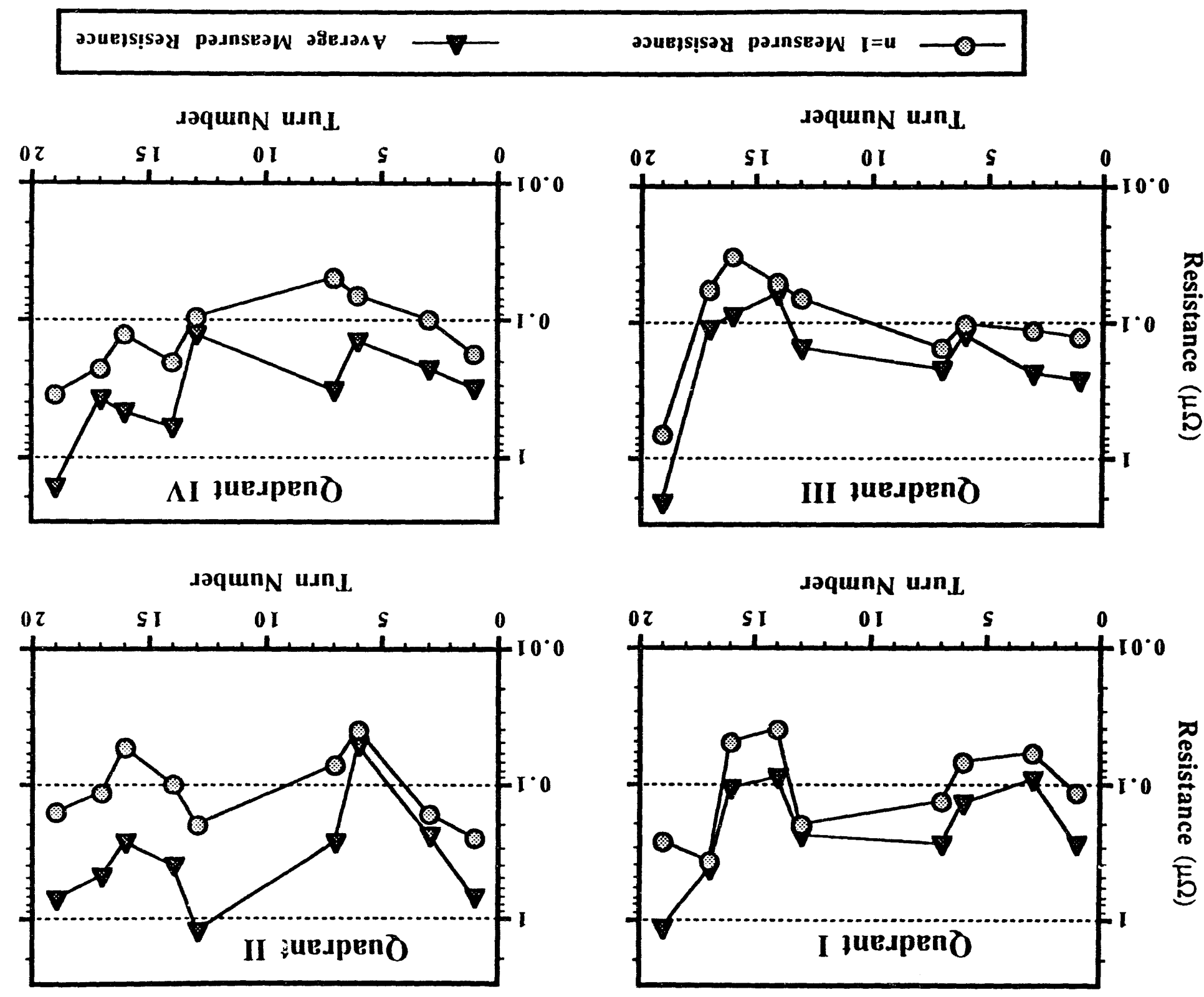

$r$ - ZIE $\forall$ OO 


\section{DCA 312 - M}
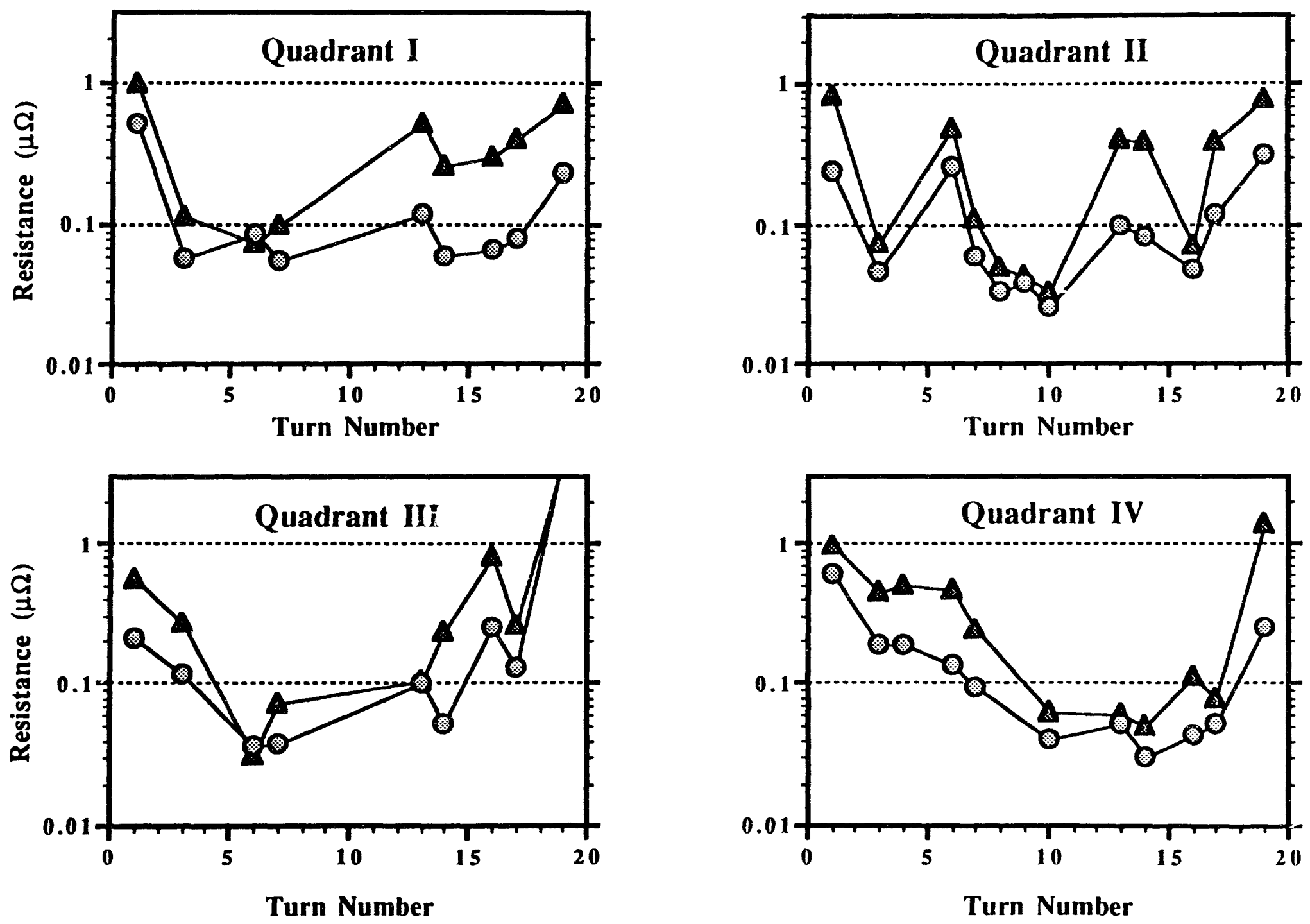

\section{- $n=1$ Measured Resistance $\rightarrow-$ Average Measured Resistance}


DCA 312 - C
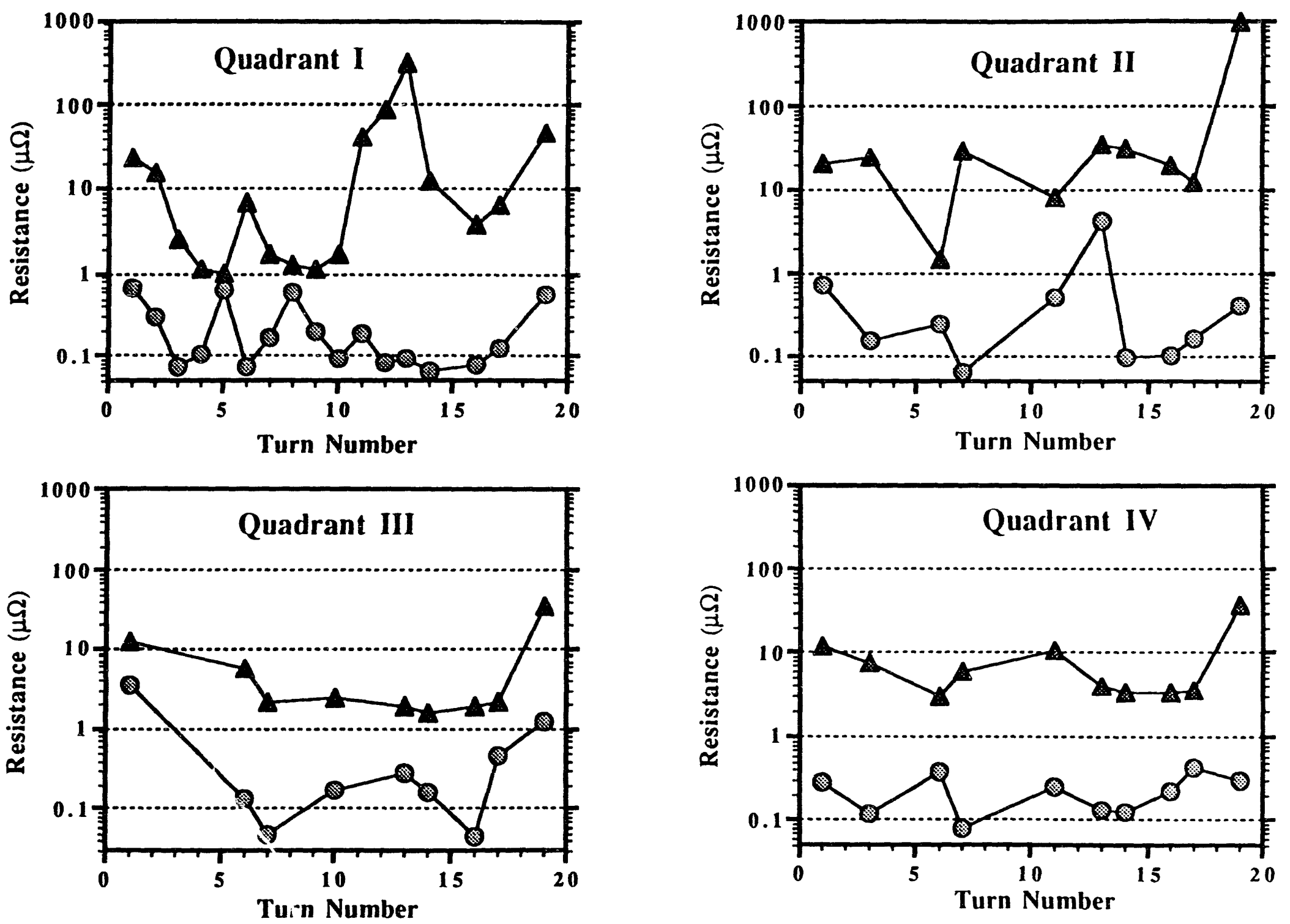

$$
\text { - Adjacent Contact Resistance } \rightarrow-\text { Crossover Contact Resistance }
$$

13 
DCA 312 - E
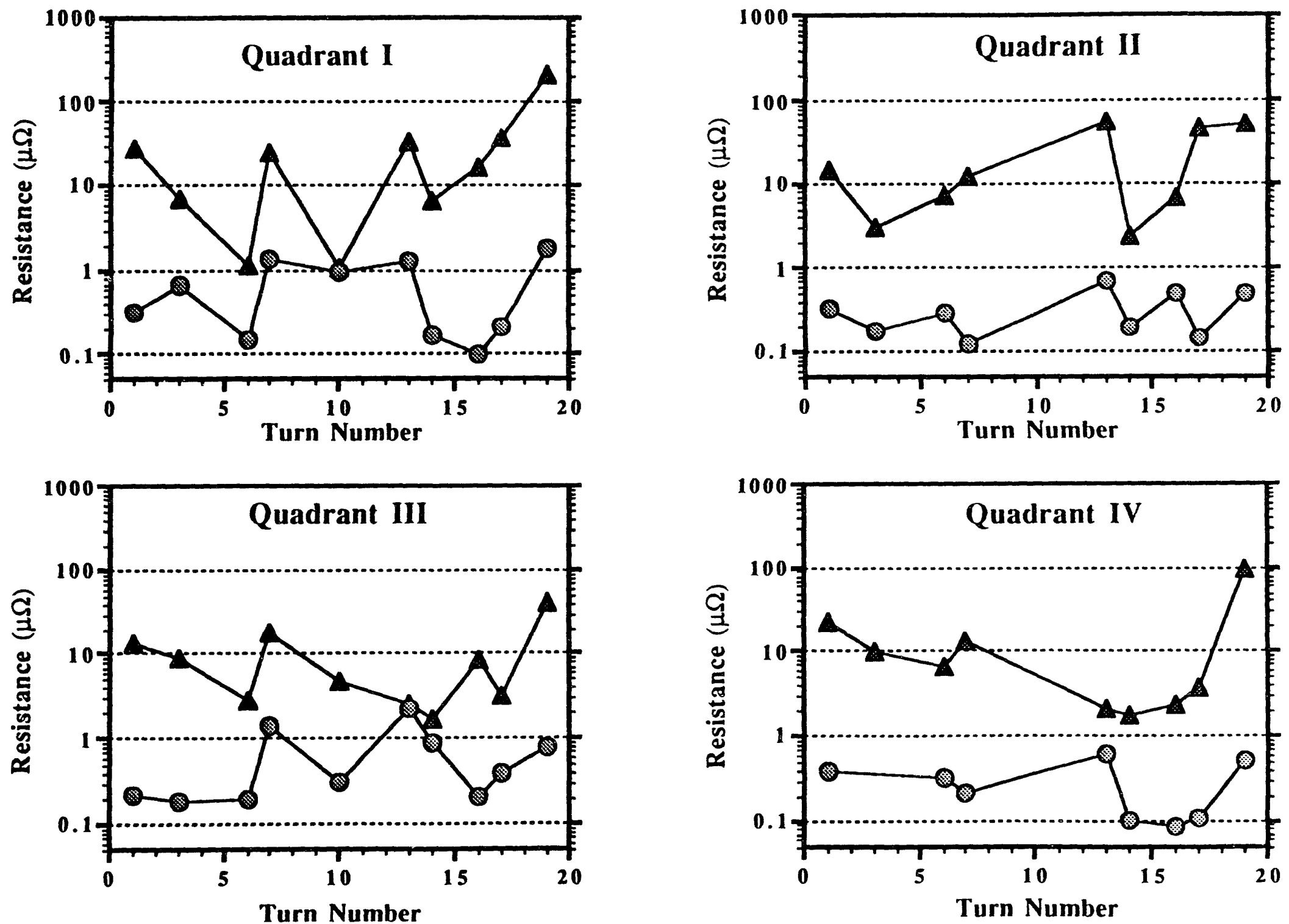

$\rightarrow-$ Adjacent Contact Resistance $\rightarrow-$ Crossover Contact Resistance 
DCA 312 - J
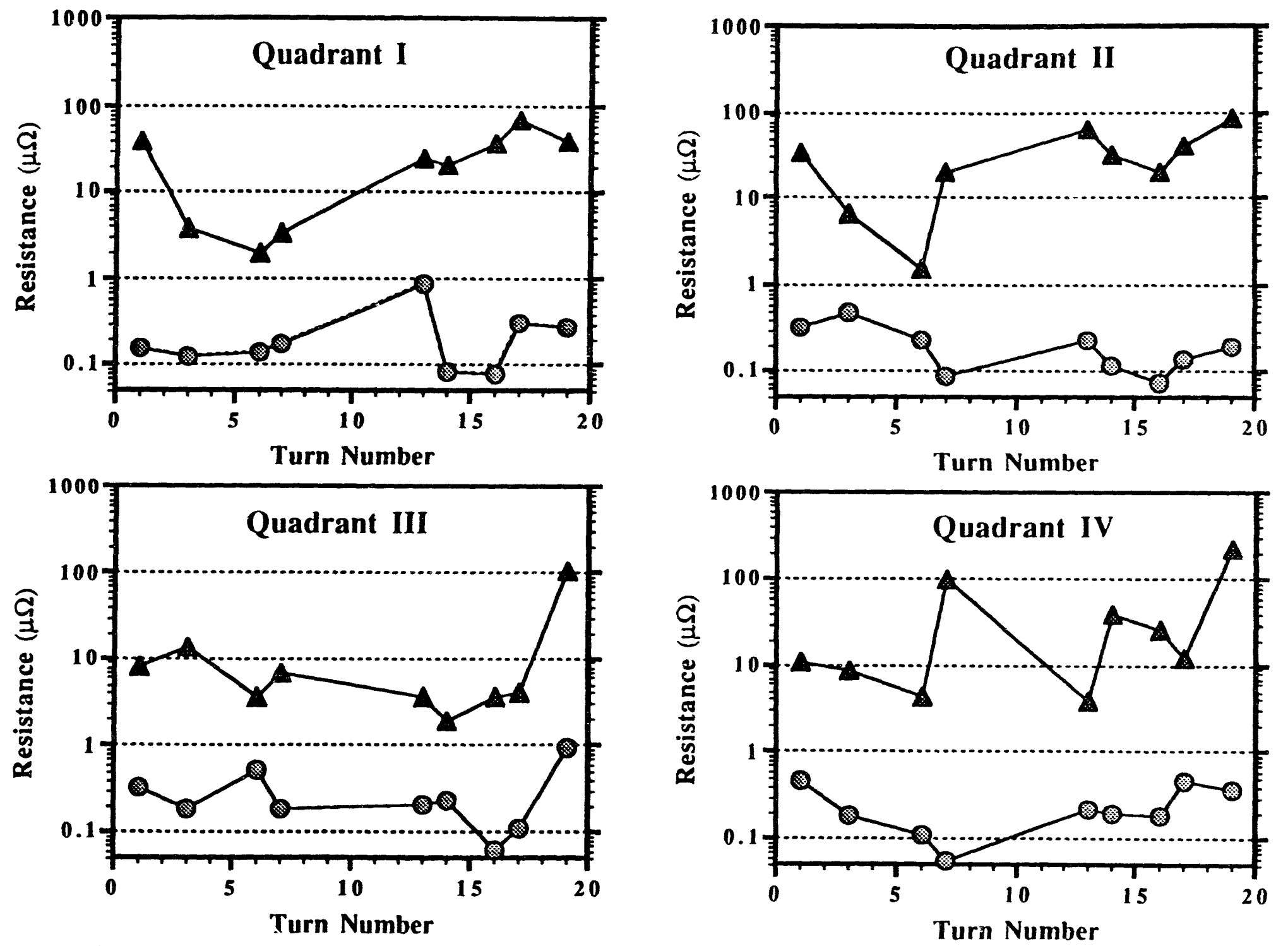

- - Adjacent Contact Resistance $\longrightarrow$ Crossover Contact Resistance 


\section{DCA 312 - M}
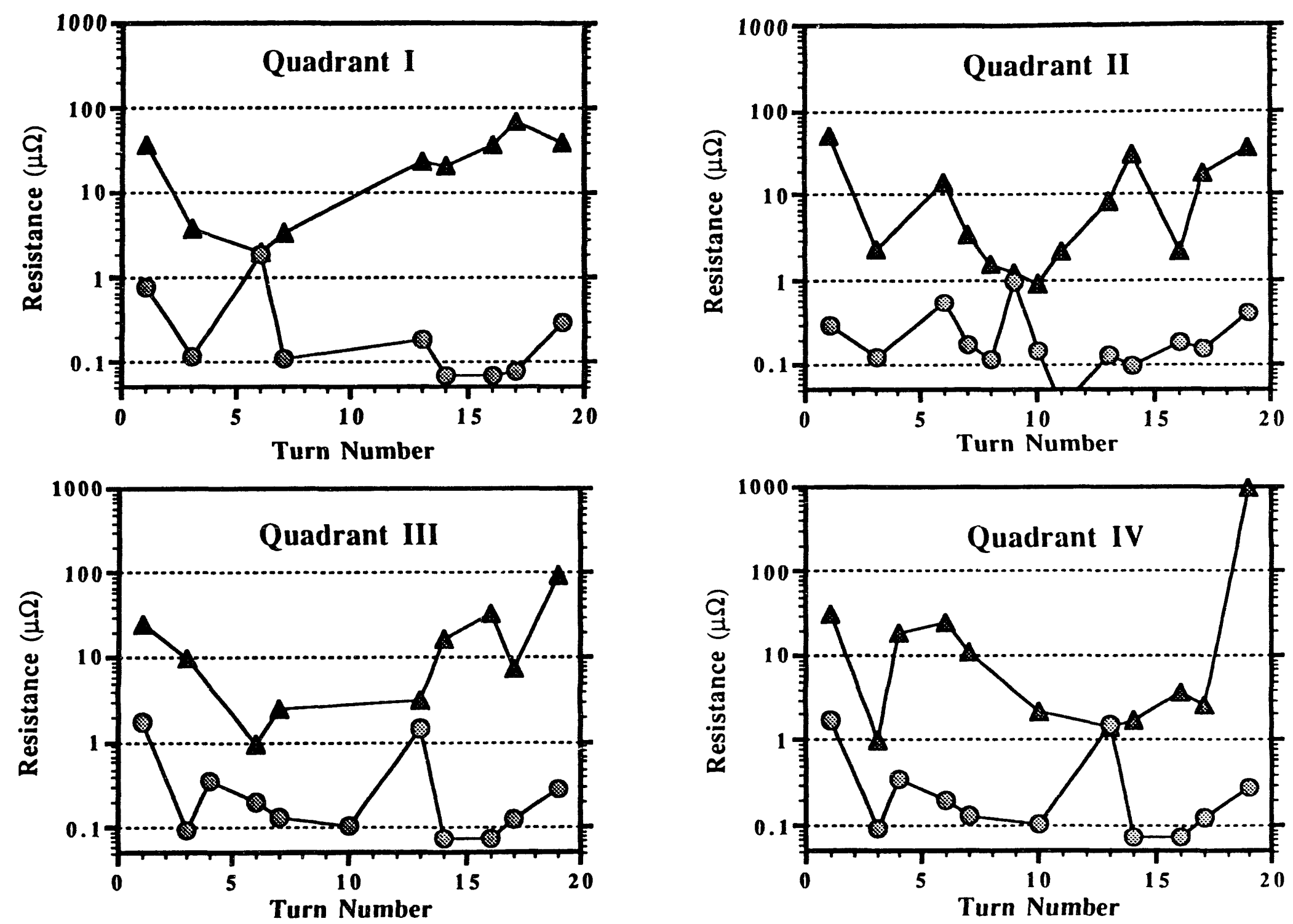

- - Adjacent Contact Resistance $\longrightarrow$ Crossover Contact Resistance 


\section{APPENDIX II}

At the conclusion of the interstrand resistance testing of the magnet sections, two cable turns (section E, quadrants I \& III, turn 19) were selected for additional testing in order to establish the statistical validity of the test procedure. Two additional tests were performed. The effect of thermal cycling on the reproducibility of the interstrand resistance measurements was established by remeasuring the standard strand sample set as initially instrumented after warming the magnet section to room temperature overnight, cooling to $4.2 \mathrm{~K}$ and remeasuring. After again warming the magnet section to room temperature, turn 19 quadrant III was rewired so that each of strands 1-16 were instrumented. The interstrand resistance of all pair combinations of strands 1.8 and strands $9-16$ were measured. The section was then warmed again, strands 16-30 and strand 1. were instrumented and the interstrand resistance of all pair combinations of strands 16-23 and strands 24-1 were measured. In this way four nominally identical subsets of 28 interstrand resistance measurements were created. These data sets were compared to data from the standard strand sample set (Figure 1 in the main text) to establish the representativeness of the standard sample. This expanded strand sample set contained the interstrand resistance of all adjacent strand pairs so that the range in adjacent interstrand resistance could be examined. In addition certain strand pairs were measured in both the standard strand sample set and, after being disconnected and reinstrumented, so that the effect of reinstrumentation on reproducibility was explored.

\section{AII.1 Reproducibility of Individual Measured Interstrand Resistances}

Resistance values were repeated after one thermal cycle to within $\pm 1.2 \%$ in all cases, average repeat measurements were $99.88 \%$ and $100.77 \%$ of the original values for turn 19 in quadrants I and III, respectively. There were 9 strand pairs in turn 19 QIII that were remeasured after thermal cycling and reinstrumentation. Resistance values for these pairs were repeated to within $\pm 1.8 \%$, average $99.74 \%$.

\section{AII.2 Spread in the Data}

The model for evaluating individual crossover and adjacent strand resistances from measured values assumes identical resistance for all crossover contacts as well as for all adjacent contacts. Measured resistance values are influenced by both crossover and adjacent resistances, low strand separation pairs most heavily influenced by adjacent strand contacts and pairs with strand separation near N/2 most heavily influenced by crossover contacts. Figure AII-1 shows the spread in measured resistance of adjacent pairs from the expanded set of measurements taken from turn 19, quadrant III of magnet section $E$. Values ranged from $0.633 \mu \Omega$ to 2.005 , averaging $1.276 \mu \Omega$. The apparent bimodality ( 1.0 and $1.5 \mu \Omega$ ) of the distribution in Figure AII-1 may be due to the magnet section length being slightly longer than one cable twist pitch. If adjacent strand contact is mainly at the rollover point along the cable edge, some strand pairs, having three rollover points in the test section instead of two, will have less resistive contacts. The observed spread in measured adjacent strand resistance and their low absolute value is significant with regard to the evaluated resistances derived from linear fits to plots of conductance and $N /\left(N n-n^{2}\right)$, particularly since there is only one of these data points in a standard sample set. For example, if the adjacent strand resistance had been measured between strands 11 and 12 instead of 1 and 2, the crossover and adjacent resistances would change by $-24 \%$ and $62 \%$, 


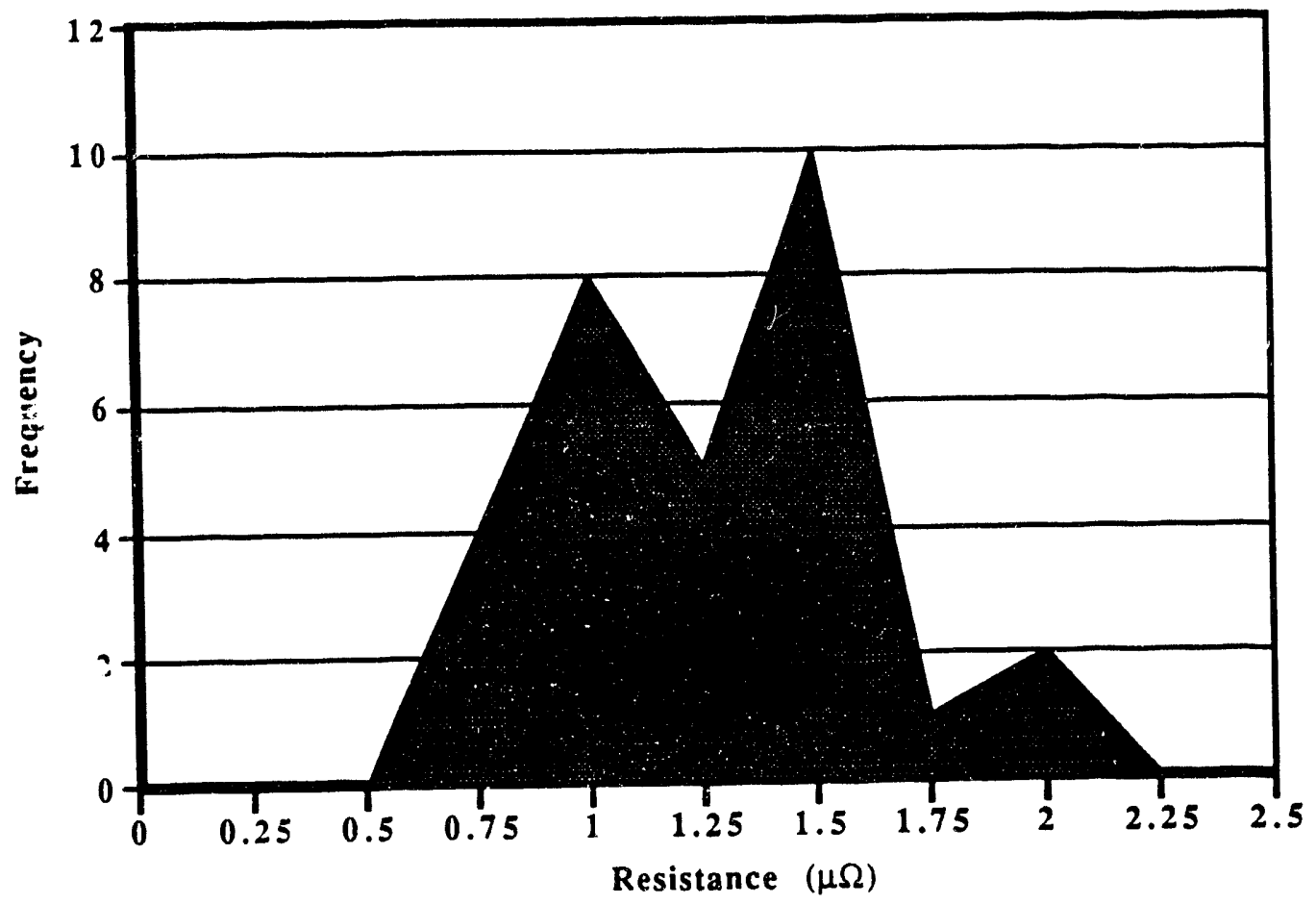

Figure AII-1. Distribution of 30 measured adjacent strand resistances for turn 19, quadrant III, section E.

respectively. This suggests that an average of several data points, especially at low strand separations, would provide more reliable evaluated interstrand resistances. Only two strand pairs with maximum strand separation $(n=15)$ were measured, so that no significant data is available regarding the spread in crossover contact resistance.

\section{AII.3 Representativeness of Standard Sample Set}

Conclusions reached in the main body of this report are based in part on the assumption that data obtained from the 28 interstrand resistances observed from strand pairs in the standard sample set of 8 strands is representative of the 435 interstrand resistances of all pairs of all 30 strands. The standard sample set was chosen to provide a broad range of strand separations and to include the set of 6 strands reported in previous work. The assumption that this sample is representative was investigated by measuring a larger group of strands for one turn (turn 19, quadrant III, section E) of the magnet coil. This expanded sample set included all 30 strands divided into four groups of 8 or 9 strands each. Some strands were included in two groups in order that all adjacent strand pairs could be measured. Figure AII-2 shows all of the measured interstrand conductances as a function of $N /\left(N n-n^{2}\right)$. A linear fit for each data subset and for the average of all data is also displayed, the chick solid line is for the averaged data, the dashed line for the standard sample set and the fine solid lines for the four subsets of the expanded data set. Table AII1 contains the crossover and adjacent resistances evaluated from these linear fits, as well as the average measured resistances. The standard set is expected to have a larger average 


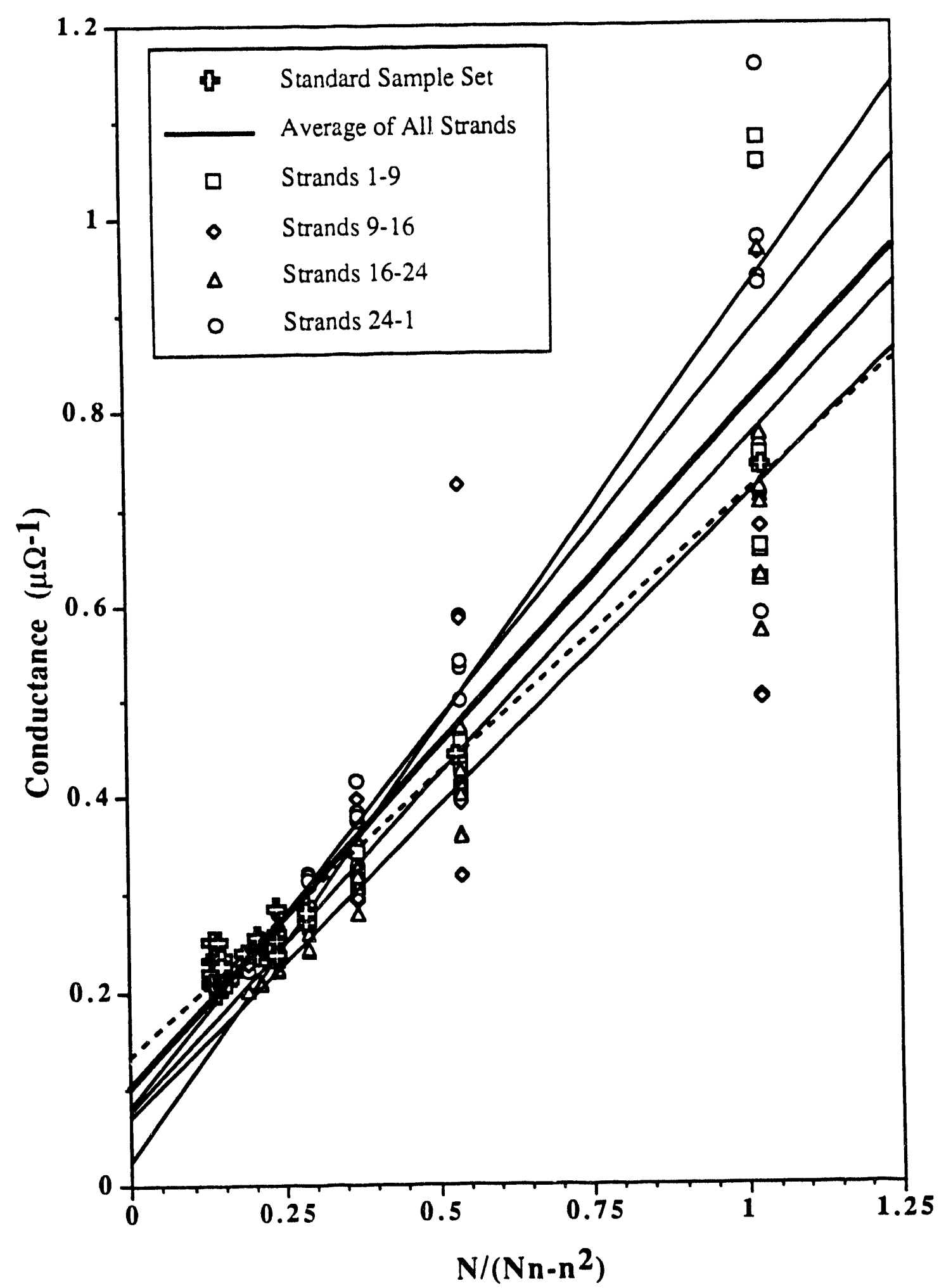

Figure AII-2. The interstrand conductance for five subsets of 28 measurements from tum 19, quadrant III, section $E$ as a function of $N /\left(N n-n^{2}\right)$. Linear fits to each of the four identical subsets are displayed as fine solid lines, the fit to the standard sample set is a dashed line and the fit to the average from all subsets at each $N /\left(N n-n^{2}\right)$ value is a thick solid line. 
Table AII-1. Average measured resistance and evaluated individual crossover and adjacent resistance for each of five independent subsets of 28 resistance readings from tum 19, quadrant III, section E of magnet DCA 312.

\begin{tabular}{|l|c|c|c|}
\hline Data Subset & $\begin{array}{c}\text { Average Measured } \\
\text { Resistance }(\mu \Omega)\end{array}$ & $\begin{array}{c}\text { Evaluated Adjacent } \\
\text { Strand Resistance }(\mu \Omega)\end{array}$ & $\begin{array}{c}\text { Evaluated Crossover } \\
\text { Resistance }(\mu \Omega)\end{array}$ \\
Standard & 4.099 & 1.74 & 229 \\
Strands 1-9 & 2.725 & 1.46 & 385 \\
Strands $9-16$ & 2.677 & 1.12 & 1250 \\
Strands $16-24$ & 3.036 & 1.58 & 422 \\
Strands 24-1 & 2.519 & 1.28 & 366 \\
All Combined & 2.739 & 1.44 & 303 \\
\hline
\end{tabular}

measured resistance because there are more high strand separation measurements in it. One can see from Table AII- 1 that crossover resistances can be the most affected by different choices of sample strand sets. Evaluated adjacunt strand resistances are not greatly affected. The standard sample set used for conducting the measurements on all sixteen quadrants gives results which are probably representative of the whole within a factor of two for crossover resistance and $20 \%$ for adjacent resistance. The standard set does yield the lowest crossover resistance and the highest adjacent resistance of these data sets. There is some indication in Figure AII-2 that this may be because much of the data comes from strand pairs of relatively high separation. Figure AIl-3 compares the measured resistance from the standard set of data with the resistance of strand pairs from the

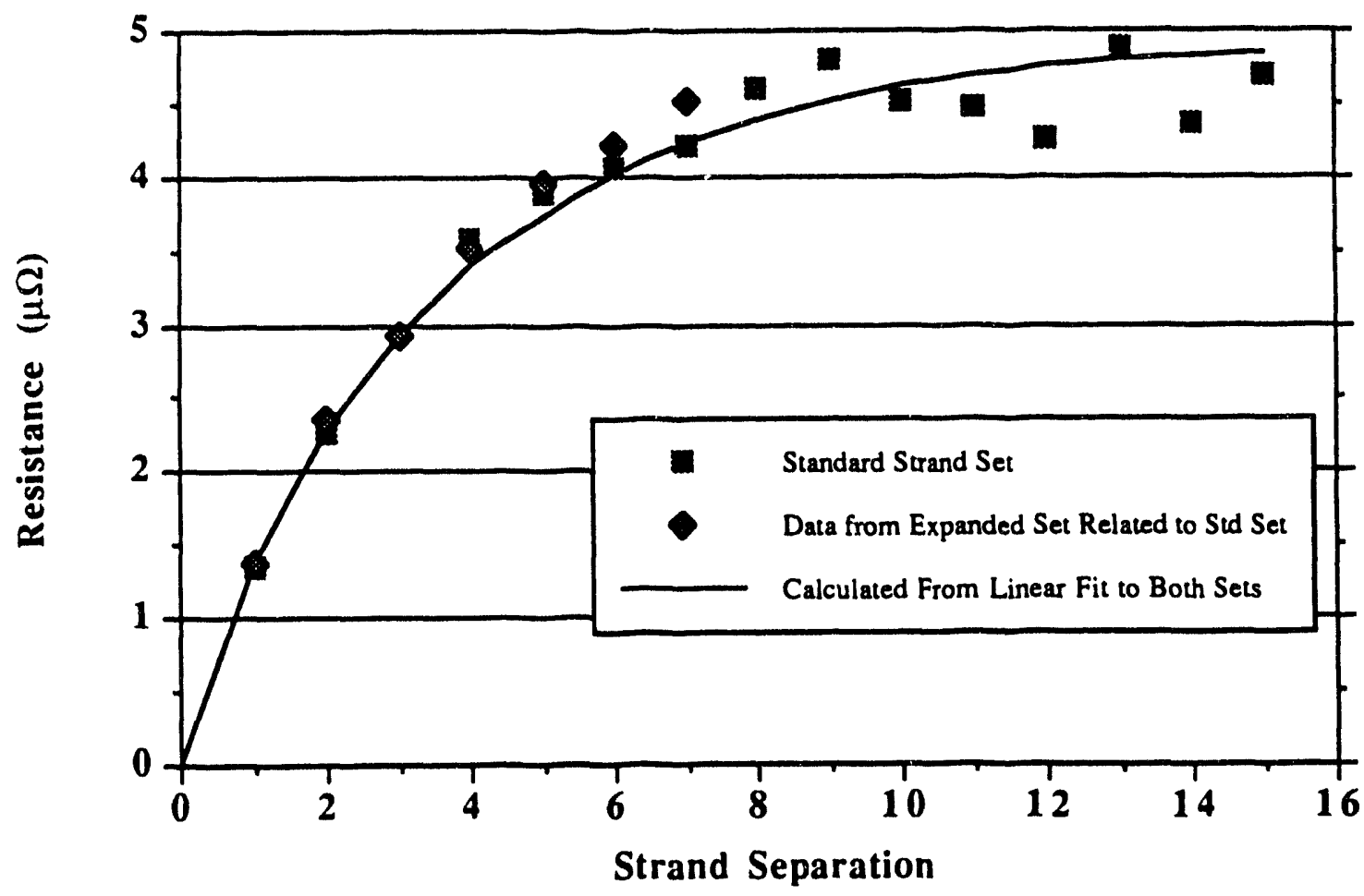

Figure AII-3. Interstrand resistance of the standard sample set compared to the interstrand resistance of related strand pairs from the expanded set. A fit to both sets of data combined based on a linear fit in $1 / \mathrm{r}$ and $\mathrm{N} /\left(\mathrm{Nn}-\mathrm{n}^{2}\right)$ coordinates is also displayed. 
expanded set which have at least one strand in common with the standard set. It is clear from Figure AII-3 that including low strand separation measurements in this data set does not significantly change its character. The crossover and adjacent resistances from the expanded sample set data in Figure AII-3 are within 14\% and 3\%, respectively, of the values reported in Table AII-1 for the standard sample set. This variation is within the range of values for the other four subsets of data. 

$+$

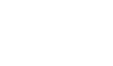

